\title{
Efficiency as a Precursor to Precarity in the Food Industry
}

\author{
John Esposito
}

Chukyo University

\begin{abstract}
Food has been an integral part of the industrial project since its inception. Productivity gains on the farm created the surplus labor force that was absorbed by the expanding industrial sector. The new jobs in factories, mills, and mines were unlike the small-scale farms and family businesses they replaced because they were based on a set of modern values that flourished alongside capitalist expansion. Instead of working according to rhythms attuned to natural and bodily cycles, for instance, industrial workers were required to follow a mechanized logic. The tyranny of the clock was reinforced by a priority on repetitiveness, speed, deskilling, and specialization-all in the name of greater efficiency. A look at the food industry today, in particular those workers upon whose labor it depends, suggests that their increasing precariousness is predicated on the institutionalization of these values. Whether it be the illegal immigrants found on industrial farms and in food processing plants or the part-time staff that predominate in restaurants and supermarkets, the food industry as a whole represents an ideal point of departure for coming to terms with the constellation of values that lend ideological support for increasing precarity in the world of work.
\end{abstract}

Keywords: capitalism; ideology; labor laws; values; work 